\title{
Evaluating the implementation of health coaching in a rural setting
}

\author{
Kaye E. Ervin ${ }^{1}$, Vivienne J effery ${ }^{2}$, Alison Koschel ${ }^{3}$ \\ 1. University of Melbourne, Cobram, Victoria, Australia. 2. Numurkah District Health Service, Numurkah, Victoria, \\ Australia. 3. Hume Medicare Local, Victoria, Australia.
}

Correspondence: Kaye E. Ervin. Address: University of Melbourne, PO Box 252, Cobram, Victoria, Australia. E-mail: ervink@humehealth.org.au

Received: August 28, 2012

Accepted: September 17, 2012

Published: December 1, 2012

DOI : $10.5430 /$ jha.v1n2p17

URL: http://dx.doi.org/10.5430/jha.v1n2p17

\section{Abstract}

Objective: The aim of this project was to explore the barriers and enablers to implementation of staff training in Health Coaching, a model of care employed in primary care to facilitate client self-management of chronic disease.

Methods: Forty six staff members from five rural community health settings were recruited to undertake training in Health Coaching. A simple post training quantitative evaluation was conducted by surveying staff five months post training.

Results: There was a $68 \%$ response rate to the surveys. Only $50 \%$ of staff trained in Health Coaching reported implementing it into practice. Enabling factors to implementing the training were reported as peer and organizational support.

Conclusion: Effective models of self-management in chronic disease should not be aimed at staff training alone. This study suggests that implementation of new models of care requires a significant change in clinician practice which is not readily embraced by staff.

\section{Key words}

Chronic disease, Early intervention, Self-management, Staff training, Training implementation

\section{Objective}

The aim of this study was to explore staff perceptions of barriers and enablers to the implementation and routine use of health coaching training.

Health coaching is the practice of health education and health promotion within a coaching context, to enhance the wellbeing of individuals and to facilitate the achievement of their health-related goals ${ }^{[1]}$. Effective health coaching engages the patient as a partner in self-management, rather than being a passive recipient of care ${ }^{[2]}$. The benefits of this approach are multi factorial, including better compliance, greater continuity of care, improvements in health status and reduced hospital admissions ${ }^{[3,4]}$. 
Engagement of health care professionals is viewed as critical for successful application of self-management education programs ${ }^{[5]}$. Self-management is becoming recognised as a vital aspect to help manage chronic disease ${ }^{[6]}$ with public health policy now having self-management as an intervention ${ }^{[7]}$. Numerous studies have investigated the benefits of self-management strategies aimed at improved health outcomes ${ }^{[8-11]}$. Investigating staff uptake, integration and delivery of self-management tools and training appears limited. There is even more limited evidence of the use of self-management techniques and staff uptake in rural settings, despite the high prevalence of chronic disease. One Australian study of staff implementation of self-management of chronic disease suggested that maintaining ongoing capacity, especially in rural areas, requires planned and structured professional development opportunities ${ }^{[12]}$.

A previous study suggested that areas to investigate include slow embracing of self-management concepts, reluctance to develop care plans, and the need to evaluate the contributions of the roles of the health professional ${ }^{[13]}$. Other authors ${ }^{[9,14]}$ suggest further research to address mechanisms that make coaching successful and ultimately facilitate its integration into routine health care through a wide range of health professional groups. Recently, a report in the UK called for the need to explore clinicians' attitudes, behaviors and beliefs of self-management principles, if we hope to integrate it into routine health care ${ }^{[15]}$.

\section{Background}

Early Intervention in Chronic Disease (EIiCD) is an Australain government initiative which forms an integral part of the Victorian Government Department of Health’s Integrated Chronic Disease Management strategy ${ }^{[16]}$.

Three year recurrent funding was received for an EIiCD program in a rural local government area. This was a partnership consortium involving four small rural health services and one home and community care (HACC) agency. The purpose of the funding was to facilitate effective models of self-management for clients with chronic disease. In Australia, people living in rural areas tend to have shorter lives and higher levels of illness and disease risk factors than those in major cities ${ }^{[17,18]}$. It is therefore imperative that rural health practitioners are knowledgable about efficient and effective chronic disease management strategies.

The rural health services in this study were a combination of integrated primary care services and outreach models. 'Integrated services' offer a range of integrated primary health care services from the hospitals located in the communities they serve. Integrated services provide single point access to a range of services and sufficient numbers of health professionals to ensure mutual professional support. Because these communities cannot usually sustain necessary allied health and specialist services in a discrete form, this model enables the population to sustain such a service ${ }^{[17]}$. The HACC service was an integrated primary care service, but was not co located at the community's hospital.

'Outreach models' are characterized by the periodic supply of services from one location which has services to other locations which do not. The arrangement involves centrally located services providing services to satellite communities though a 'hub and spoke' arrangement, such as where an allied health professional or expert clinician in one community may visit a second community for short periods. Outreach services thus improve access to health services for widely dispersed and isolated populations and often co-exist with other integrated and comprehensive primary care services ${ }^{[17]}$.

Three of the rural health services and the HACC service were located in similar size towns of approximately five thousand people who rely primarily on agriculture, at least 30 minutes from the nearest major regional centre. The staffs employed at each service are a similar mix of nurses and allied health staff. One rural health service was located in an agricultural 
town of approximately 1,500 people, 45 minutes from the nearest regional centre. This service has smaller numbers of allied health staff, working under an outreach model.

\section{Methodology}

\subsection{Training Model}

The training model chosen to facilitate client self-management was Health Coaching Australia. Health Coaching (HC) is described as a model that incorporates a number of well-regarded health behaviour change theories and principles into a structured 10 step process that guides health practitioners in facilitating agenda-setting, decision making and behaviour change planning ${ }^{[19]}$.

\subsection{Participants}

A total of 46 staff members across the five sites undertook the training. The training places were allocated in relation to the amount of effective full time positions per organisation working with the likely EIiCD target population. There were four staff from site 1, twelve staff from sites 2 and 3, eight staff from site 4 and 10 staff from site 5.

\subsection{Evaluation}

Quantitative data collection was chosen to evaluate implementation of the training. The project manager identified staff members who had undertaken HC training, and distributed surveys via managers at each site. Management was not aware which participants returned surveys.

\subsection{The survey tool}

As no specific validated tool existed, the formal survey tool was constructed by the project manager and a researcher, based on staff feedback, to elicit information relating to perceived barriers and enablers to converting HC training into everyday clinical practice. The survey consisted of 11 questions and areas explored by the survey included the time taken to commencement of implementation of the health coaching principles into practice, barriers to implementation, and the percentage of clients that staff used HC with, and the most common element/s of the HC tools used.

Basic demographic data was collected including participant age, years in allied/nursing health workforce and current position's held. The survey also sought to determine staff's perceptions of the level of support, both within their own organisation and across the health services in the LGA. Finally two open ended questions provided opportunity to express opinions not covered by the survey and possibly unearth enablers or positive aspects not identified.

The survey was pretested to ensure clarity and participant understanding. As no other relevant and validated tool was available in the literature, and because the information was sought to determine local rural barriers with an aim of facilitating local solutions, the tool was developed and validated this way. Consistent responses during the pretesting phase and obtained from the study participants indicated reliability of the tool. Psychometric testing of the tool is not appropriate in this case, as a resulting score that implies an outcome, is not the aim of this tool or this study.

\subsection{Ethics approval}

Ethical approval for the project was granted by Goulburn Valley Health Research and Ethics Committee, approval number GVH 07/10. 


\section{Results}

Forty four formal surveys were distributed with 30 respondents, giving a 68\% return rate. The respondent return rate was fairly evenly distributed across the sites, with a $75 \%$ (3 and 9 respondents respectively) return rate from sites 1 and 2, 66\% (8 respondents) at site 3 and 61-2\% (5 and 6 respondents) at sites 4 and 5 respectively.

There was a wide age range and years of service represented in the group. The basic demographic data was combined to produce the described sample represented in Table 1. Although not represented in the table, the characteristics of the non-respondents did not differ greatly from those who did respond.

Table 1. Demographic information of survey respondents

\begin{tabular}{ll}
\hline Participant details & Demographic details \\
\hline Age range of respondents & $24-61$ years \\
Average age of participants & 44 years (1 missing data) \\
Range of total years in AHW & 1 -35 years \\
Average total years in allied health workforce & 13.4 years \\
Respondent positions in health service: & \\
Dietician & 1 \\
Diabetes educator & 1 \\
Counsellor & 3 \\
Podiatrist & 3 \\
Physiotherapist & 1 \\
Community Health Nurse & 6 \\
Occupational Therapist & 2 \\
Assessment Officer & 2 \\
Allied health assistant & 1 \\
Intake officer & 1 \\
District Nursing Service & 6 \\
Registered Nurse Acute & 1 \\
Health Promotion Assistant & 1 \\
Health Promotion Officer & 1 \\
Not stated & 1 \\
Total (1 respondent listed 2 professions) & 31 \\
\hline
\end{tabular}

There were no major differences when the results were stratified by site and so the results are pooled for presentation. The majority of respondents to the survey (73\%) described their attendance at the HC training as being nominated and directed by their manager, as opposed to voluntary (13\%) or actively sought by the employee (13\%).

When respondents were asked how long it took them to commence implementation of the new skills learned in training, $40 \%$ identified that they immediately implemented it. Smaller numbers responded that they were still not using it, or that it took two weeks to two months to commence implementation. There were 4 staff members (13\%) who nominated differing time frames. There was no correlation between respondent's age or years in the workforce to the time frame for implementation. Similarly, when a Pearson correlation coefficient was computed to assess the relationship between organizational support and the time taken to implement the new skills, no correlation was found $(r=0.06, \mathrm{n}=31, p=0.74)$.

Staff was asked to report on limitations to the use of HC into practice as a whole. The items for consideration were: relevance of the training to practice, the time required to implement training, colleague's opinions and support, manager's opinions and support, knowledge, how to implement training, where and what documentation to use, and experience and confidence in using HC. The percentage responses are shown in Figure 1. The greatest limitation to use of HC is reported 
as the time required using it and how to implement training into work practice. In all other domains, no limitations to use are predominant.

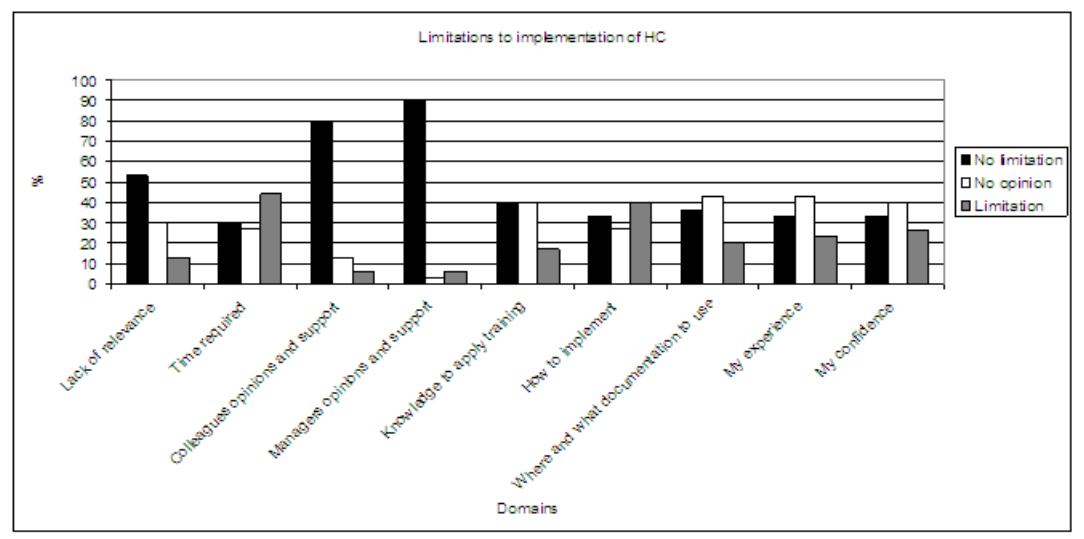

Figure 1. Reported limitations to the use of HC in the workplace (30 responses)

Half of respondents (50\%) to the survey reported using HC with 50\% of their clients. 3\% of respondents reported that they were still not using it when surveyed 5 months post training, with the same number reporting that they used it with all their clients. Pearson correlation coeeficient was computed to assess the relationship between peer support within their organisations and staff's use of skills (based on categorised percentage of use). There was no correlation between the two variables $(r=-1.5, \mathrm{n}=31, p=.40)$.

HC teaches a number of techniques/processes to staff to facilitate client self-management. The major tools and their descriptor are shown in table 2 with responses to which form of HC was most commonly used by participants. Staff were asked the most common form of HC used, and were instructed that they could choose more than one.

Table 2. Principles of Health Coaching and their description [Source: (19)]

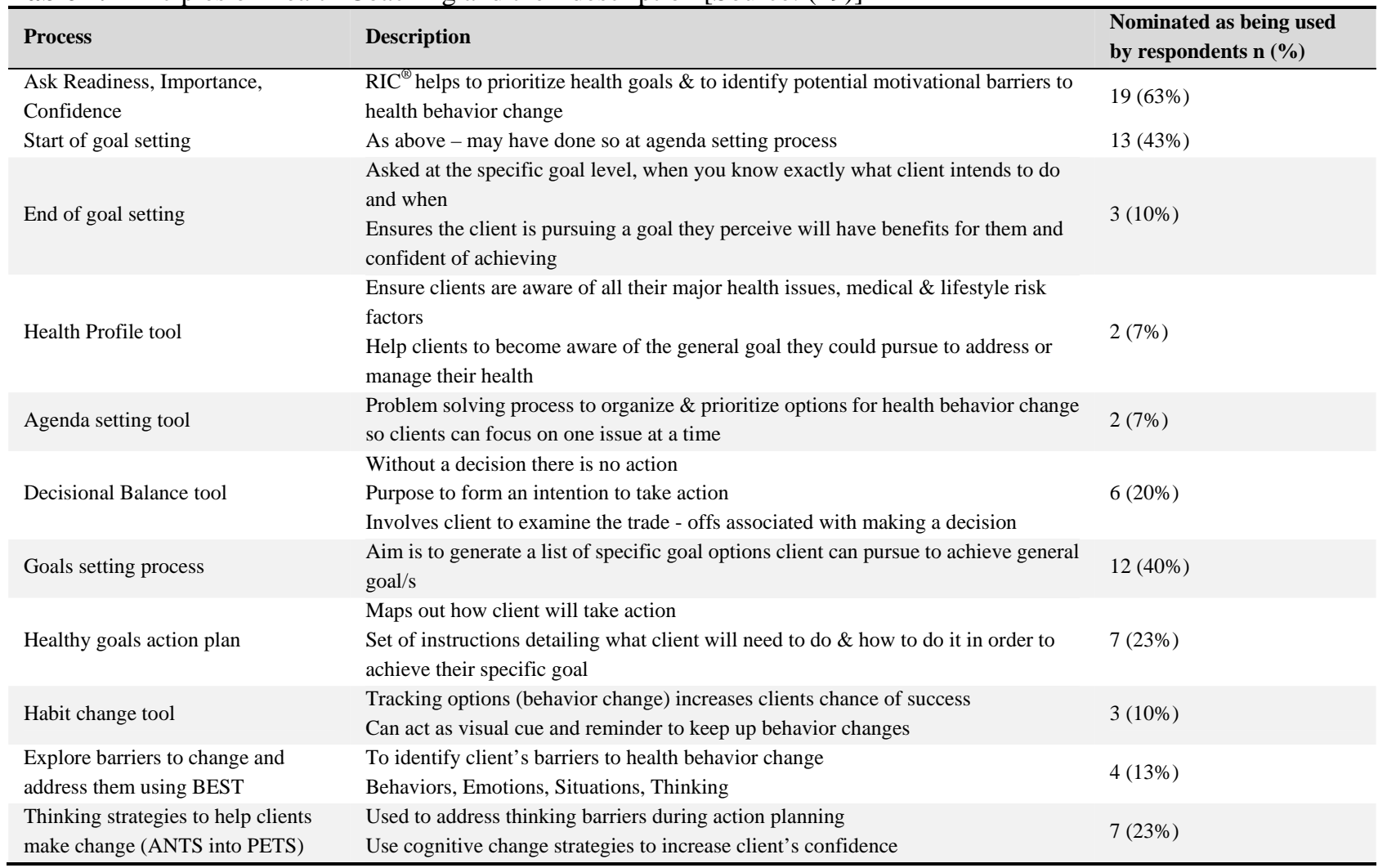


The Readiness, Importance, Confidence (RIC ${ }^{\circledR}$ ) principle was the most frequently used principle with 19 respondents declaring they commonly used this tool. Using $\mathrm{RIC}^{\circledR}$ at the start of goal setting, and the goal setting process were the next most frequently used tools to facilitate client self-management, with 13 respondents and 12 respondents respectively reporting use of these.

The level of support was the next section explored by the survey. More than half of the respondents felt there was a good level of support within their organization, and this is depicted in Figure 2. As previously reported, this did not influence the time it took to implement the skills, nor the percentage of clients they used HC with.

\section{Staff perceived level of support within their own organisation}

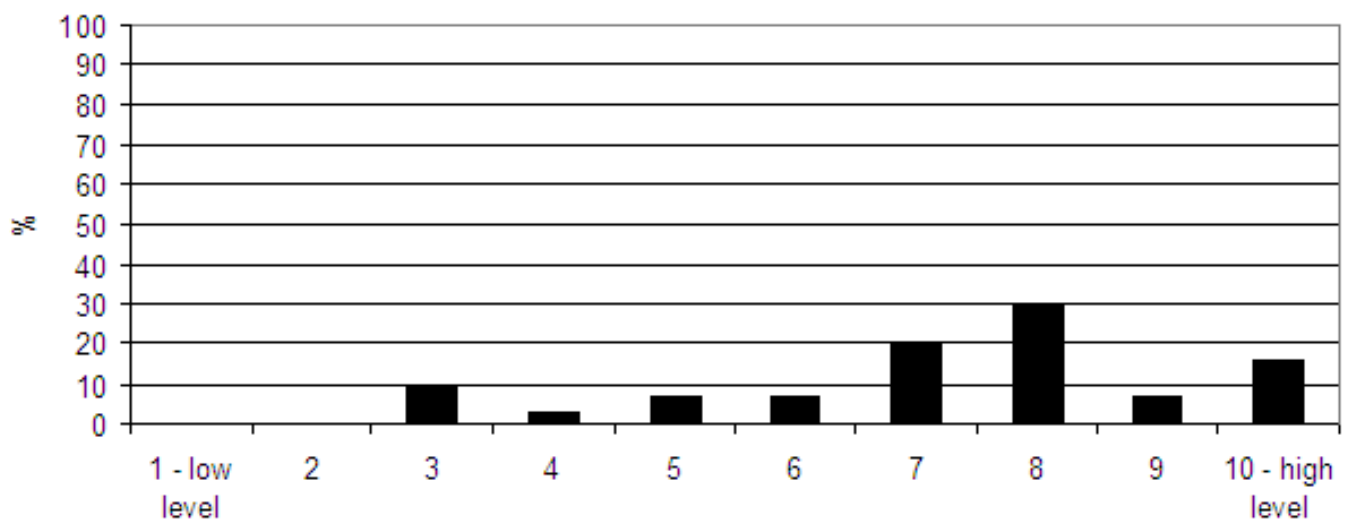

Level

Figure 2. Reported level of peer support within own organisations

The final section of the survey included 2 open ended questions. Because the responses were brief written answers, a simple content count was conducted, essentially a quantitative presentation of qualitative responses. In the first, staff was asked to list any factors that they felt assisted with the implementation of HC. There were 3 clear areas discussed by the 12 participants (40\%) who elected to respond. It was mentioned 7 times that the HC principle of goal setting was favourably received by clients with responses such as;

"Clients like goals" and "[Health Coaching] Enables you to focus more on clients goals and ask them what they feel as important rather than assuming."

Peer and management support was also expressed as an important factor in applying HC principles. Four responses listed networking and meeting with peers as being important factors in implementing HC, with responses such as;

"Networking" and ".......meeting and talking to others, giving ideas" and "Regular meetings to discuss HC and to demystify fears"

Staff also reported that utilising the RIC ${ }^{\circledR}$ principle also assisted implementation. Three responses were that RIC ${ }^{\circledR}$ assisted in applying the principles, with statements like;

"Feel that I ask RIC which helps me most in counselling" and "Having an action plan with RIC prompts". 
Fourteen staff members (47\%) responded with other comments regarding HC training or implementation. Time constraints related to paperwork was reported most often as a predominant barrier in implementing the training, in keeping with the quantitative responses in the survey. Responses included;

\section{“Time constraints associated with paperwork...” and "Paperwork is time consuming”}

\section{Conclusions}

The age range of participants and years of experience in the workforce was broad. Although staff worked in various disciplines, the majority had a background in nursing. This is consistent with other findings ${ }^{[20]}$ that the majority of those who are trained in health coaching are nurses and the remainders are non-psychologists from allied health fields.

Most staff reported that they had been nominated and directed to undertake the training, rather than voluntarily seeking it out. There is a great deal of literature concerning mandatory versus voluntary training and the subsequent transfer of training into practice ${ }^{[21,22]}$ with most suggesting that voluntary training is preferable for successful outcomes. Conversely, earlier authors ${ }^{[23]}$ argue that training success was associated with mandatory attendance.

Kirkpatrick's model of training analysis in attempting to assess training effectiveness describes four levels: (1) trainee reactions, (2) trainee learning, (3) trainee transfer and (4) organizational outcomes ${ }^{[24]}$. This study focused on the third level. As trainee transfer directly influences organizational outcomes (in this instance client self-management) this element was the major focus. It stands to reason that without good uptake of trainee transfer there will be little influence on client results.

Despite workplace incentives to undertake further training in Australia, the uptake is poor in rural areas. Staffs rarely self-nominate to undertake further education, citing lack of replacement for their clinical load and therefore impacting directly on clients and coworkers ${ }^{[17]}$.

Training implementation in the work environment occurred immediately for $40 \%$ of respondents. Organizations which provide training to staff seek transfer of the training into the workplace ${ }^{[25]}$, but the success of this is dependent on many factors, including support from supervisors and peers and opportunity to use the newly acquired skills ${ }^{[22]}$. Feedback from staff in this study supports this finding, suggesting that the successful implementation of the training was dependent on organisational support. It did not however influence the time frame for implementation nor how many clients' staff used HC with. Other earlier studies ${ }^{[23,26]}$ echo that successful transfer of training into practice is reliant on the perceived level of organizational and management support for the training.

The two major limitations identified through surveys were the time required and how to implement health coaching as a tool to self-management. Time was understood as the perceived 'additional' time required by staff to use learnt training skills. Staff reported being unable to fulfill preexisting consultation requirements and conduct 'perceived' additional health coaching. Appointment times were increased to allow time yet this appears to have had minimal impact. Training providers and others ${ }^{[27]}$ promote health coaching as a brief intervention that can be incorporated into preexisting structure, while conversely other authors ${ }^{[28,29]}$ cite lack of time as a significant challenge for practitioners to implement lifestyle interventions into routine practice, which supports the findings from this study. Time constraints appear to be particularly concerning in rural health settings, where the small numbers of staff make release periods for study and implementing the skills into practice more difficult ${ }^{[30]}$. Taking time off clinical work, or taking longer times to consult when the health professional is the sole practitioner, as is common to rural settings, increases waiting times for clients because there is no colleague to 'take up the slack' in delivery time ${ }^{[31,32]}$. Ironically this under resourcing of staff in rural areas intensifies the need and importance of clients to self-manage, rather than relying on under resourced services to manage their care ${ }^{\text {[3] }}$. 
Staff reported they had HC knowledge but did not know how to implement this newly acquired training. Butterworth ${ }^{[27]}$ discusses the absence of current standards for health coaches and the inference is the great variation in the quality and capability of those trained. Additional resources such as material guides, increased appointment times and support group meetings appeared to have had minimal impact in this study, in assisting clinicians to implement all or part of their new skill set. A previous rural Australian study suggested that to be effective a whole-of-system approach that includes system redesign to focus on continuity of care among service providers and practitioners may assist with integrating the self-management philosophy and principles into everyday practice ${ }^{[12]}$.

Participants also reported a low level of confidence in their ability to implement the training, despite perceiving it as important. When considering RIC $^{\circledR}$ (a HC acronym for readiness, importance, confidence), staff reported that their readiness and the perceived importance of $\mathrm{HC}$ were high. HC encourages participants to rate each RIC ${ }^{\circledR}$ principle on a numerical scale, with 1 being the lowest and 10 the highest. The confidence level of $90 \%$ of respondents was reported at less than 7. HC uses the rule of low confidence (considered to be scores below 7) and recommends strategies to reduce the magnitude, number or complexity of goals and or help the patient to address their barriers to change ${ }^{[19]}$. If applied to the trainees of HC, the clinical staff themselves would be identified as not being prepared for change.

Other research ${ }^{[34]}$ cites a range of barriers and enablers not explored in this study, such as including clinician beliefs and attitudes and self-efficacy. It supported previous findings ${ }^{[34]}$ of the perceived effectiveness of intervention, congruence with their role and structural and organizational factors including lack of time, reimbursement or organisational support. Responses to the survey suggest that respondents valued the training, and in theory view it as effective tool in client self-management of chronic disease, but perceive time as the major limitation to its introduction. A large study undertaken in the UK found that the best predictor of success of self-management in chronic disease was the time staff dedicated to implementing the skills ${ }^{[35]}$.

\section{Limitations}

Although 50\% of respondents reported that they had implemented HC with clients, survey responses are most likely biased toward those who have implemented the training, and those who have not implemented it did not respond. The real uptake of transfer of training into practice would be presumed to be much less than that reported.

Due to the small scale of the study, common to rural research, and associated financial constraints no pretesting of staff knowledge, motivation to undertake training or change workplace practices was attended. Evaluation was limited to the research aim of identifying perceived barriers and enablers of implementing HC by staff following training.

This small exploratory study is not intended to be generalisable, but may provide some beneficial insight for other small rural organizations.

\section{Recommendations}

Screening of individuals prior to training to determine participants' motivation to transfer training in practice is recommended. Many such validated pre training questionnaires are readily available.

A key strategy to consider, which has been identified by other studies is to promote the perceived value of the training, by clearly articulating benefits to employees, and rewarding implementation of the training and commitment to the organizational values. These recommendations are equally applicable in any training setting, not confined to rural workplaces. 


\section{I mplications}

This small, local post training evaluation has confirmed what may have been previously assumed but not often articulated-staff training does not equate to implementation. Health coaching training, in this study, appears to have had minimal impact upon clinician change in practice. HC is not routinely conducted with clients and attempts by organisations to lessen barriers to implementation have had limited success. While there is some evidence of progress this appears random, isolated and infrequent. Pre training investigation needs to be more intensive and undertaken with participants and management, so an agreed expectation of post training progress can occur.

Australia has recently moved to national registration for all health professionals with mandatory continuing professional development, which equates to approximately three study days. Although staff members are remunerated for further education, the policy ignores the difficulty rural clinicians' face in securing release time in addition to the evidence that little of the further education is translated into practice.

\section{References}

[1] Palmer S, Tubbs, I., Whybrow, A. Health coaching to facilitate the promotion of healthy behaviour and achievement of health-related goals. International Journal of Health Promotion and Education. 2003; 41(3): 91-3.

[2] Bodenheimer T, Lorig, K., Holman, H., Grumbach, K. Patient self-management of chronic disease in primary care. Journal of American Medical Association. 2002; 288(19): 2469-73. http://dx.doi.org/10.1001/jama.288.19.2469

[3] Australian Government Department of Health and Ageing. Capabilities for supporting prevention and chronic condition self-management: A resource for educators of primary health care professionals. Flinders Human Behaviour and Health Research Unit. 2009.

[4] Weeramanthri T, Hendry, S., Connors, C., Ashbridge, D., Rae, C., Dunn, M., Fittock, M., Cleary, J., O'Donahue, L., Morton, S., Swanson, N. The Northern Territory preventable chronic disease strategy - promoting an integrated and life course approach to chronic disease in Australia. Australian Health Review. 2003; 26(3): 31-42. PMid:15368818 http://dx.doi.org/10.1071/AH030031

[5] Jordan J, Osborne, R. Chronic disease self-management education programs: Challenges ahead. Medical Journal of Australia. 2007; 186(2): 84-7. PMid:17223770

[6] Kennedy A, Gask, L., Rogers, A. Training professionals to engage with and promote self-management. Health Education Research. 2005; 20(5): 567-78. PMid:15741189 http://dx.doi.org/10.1093/her/cyh018

[7] Australian Government Dept of Health and Ageing. National Chronic Disease Strategy. National Health Priority Action Council (NHPAC). 2006; Canberra.

[8] Harris M, Williams,A., Dennis, S. Zwar, N, Powell Davies, G. Chronic disease self-management: Implementation with and within Australian general practice. Medical Journal of Australia. 2008; 189(10 Suppl): S17-S20. PMid:19143580

[9] Lindner H, Menzies, D., Kelly, J., Taylor, S., Shearer, M. Coaching for behaviour change in chronic disease: A review of the literature and implications for coaching and self-management intervention. Australian Journal of Primary Health. 2003; 9(2\&3): 1-9. http://dx.doi.org/10.1071/PY03044

[10] Lorig K, Holman, H. Self-management education: History, definition, outcomes and mechanisms. The Society of Behavioural Medicine. 2003; 26(1): 1-7. PMid:12867348 http://dx.doi.org/10.1207/S15324796ABM2601_01

[11] Lorig K, Ritter, P., Stewart, A., Sobel, D., Brown, B., Bandura, A., Gonzalez, V., Laurent, D. Holman, H. Chronic disease self-management program 2-year health status and health care utilization outcomes. Medical Care. 2001; 39(11): $1217-23$. PMid:11606875 http://dx.doi.org/10.1097/00005650-200111000-00008

[12] Stone G, and Packer, T. Evaluation of a rural chronic disease self-management program. International Electronic Journal of Rural and Remote Health. 2010; 10(1203).

[13] Weeks A, McAvoy, B., Peterson, B., Furler, J., Walker, C., Swerissen, H., Belfrage, J. Negotiating ownership of chronic illness: An appropriate role for health professionals in chronic illness self-management programs. Australian Journal of Primary Health. 2003; 9(2\&3): 17-20. http://dx.doi.org/10.1071/PY03020

[14] Adelman A, Graybill, M. Integrating a health coach into primary care: Reflections from the Penn State Ambulatory Research Network. Annals of Family Medicine. 2005 July; (3 (suppl 2)): S33-S5. PMid:16049079 http://dx.doi.org/10.1370/afm.317

[15] Grazin N. Helping people help themselves. A review of the evidence considering whether it is worthwhile to support self-management. The Health Foundation Inspiring Improvement. 2011; May: 4-5.

[16] Victorian Department of Health. Victorian Population Health Survey Journal [serial on the Internet]. 2008 Date. 
[17] Wakerman J, Humphreys, J., Wells, R., Kuipers,P., Entwistle, P., and Jones, J. Primary health care delivery models in rural and remote Australia - a systematic review. BMC Health Serv Res. 2008. http://dx.doi.org/10.1186/1472-6963-8-276PMCID

[18] AIHW. Australia's health 2010. Australian Institute of Health and Welfare, No. 12, Canberra. 2010; Cat. No. AUS 122.

[19] Gale J. Health coaching guide for health practitioners: Using the HCA model of health coaching. 1st ed. Sydney: Health Coaching Australia; 2010.

[20] Gale J. Health psychology meets coaching psychology in the practice of health coaching. InPsych. 2007; June: 12-3.

[21] Noe R, and Colquitt, J., editor. Planning for training impact: Principles of effectiveness. San Francisco: Jossey-Bass; 2002.

[22] Machin A, and Treloar, C., editor. Predictors of motivation to learn when training is mandatory. 39th Annual Psychological Society Annual Conference 2004, 29th Sept - 03 Oct; 2004; Sydney, Australia

[23] Rynes S, and Rosen, B. A field survey of factors affecting the adoption and perceived success of diversity training. Personnel Psychology. 1995; 48(2): 247. http://dx.doi.org/10.1111/j.1744-6570.1995.tb01756.x

[24] Kirkpatrick D. Great ideas revisited. Training and Development. 1996; January: 54-9.

[25] Broad L, and Newstrom, W. Transfer of Training. New York: Addison-Wesley; 1992.

[26] Facteau J, Dobbins, G., Russell, J., Ladd, R., \& Kuddish, J. The influence of general perceptions of the training environment on pretraining motivation and perceived training transfer. Journal of Management. 1995; 21: 1-25.

[27] Butterworth S, Linden, A., McClay, W. Health coaching as an intervention in health management programs. Disease Management Health Outcomes. 2007; 15(5): 315-22. http://dx.doi.org/10.2165/00115677-200715050-00004

[28] Brotons C, Bjorkelund, C., Bulc, M., Ciurana, R., Godycki-Cwirko, M., Jurgova, E., Kloppe, P., Lionos, C., Mierzecki, A., Pineiro, R., Pullerits, L., Sammut, R., Sheehan, M., Taradze, R., Thireos, E., Vuchak, J. . Prevention and health promotion in clinical practice: the views of general practitioners in Europe. Preventative Medicine. 2005; 40: 595-601. PMid:15749144

[29] Laws R, Kirby, S., Davies, G., Williams, A., Jayasinghe, U., Amaroso, C., Harris, M. "Should I and can I?": A mixed methods study of clinician beliefs and attitudes in the management of lifestyle risk factors in primary health care. BMC Health Services Research. 2008; 8(44). http://dx.doi.org/10.1186/472-6963-8-44

[30] Gardner A. S, W., Renison, B., Cann, T., Vicary, M. . Supporting rural and remote area nurses to utilise and conduct research: An intervention study. Collegian 2012; 19(2): 97-105. http://dx.doi.org/10.1016/j.colegn.2011.09.005

[31] Cheffins T, Twomey, J., Grant, J., and Larkins, S. An evaluation of self-management support capacity of providers of chronic condition primary care. Australian journal of Primary Health. 2012; 18: 112-5. PMid:22551832 http://dx.doi.org/10.1071/PY11021

[32] Schoo A, Stagnitti, K., Mercer, C. and Dunbar, J. A conceptual model for recruitment and retention: allied health workforce enhancement in Western Victoria, Australia. Rural and remote health. 2005; 5(477): 1-18.

[33] Bell. E, Orpin, P.. Self-management of chronic conditions:implications for rural physicians of a demonstration project Down Under. Canadian Journal of Rural Medicine 2006; 11(1): 33-40. PMid:16454970

[34] Laws R, Williams A., Davies, G., Eames-Brown, R., Amoroso, C., Harris, M. A square peg in a round hole? Approaches to incorporating lifestyle counselling into routine primary care. Australian Journal of Primary Health. 2008; 14(3): 101-11

[35] Kennedy A, Rogers, A., Bower, P. Support for self-care for patients with chronic disease. British Medical Journal. 2007; 335: 968-70. PMid:17991978 http://dx.doi.org/10.1136/bmj.39372.540903.94 